\title{
Evaluation of the nocivity of dent and combination of dent and gouge on burst pressure of steel pipe
}

\author{
M.Allouti, C.Schmitt, G.Pluvinage and M. Lebienvenu \\ LABPS (EA 4632), Ecole Nationale d’Ingénieurs de Metz, 57045 Metz, France
}

\section{Introduction}

During the last 50 years, gas transmission pipelines have become significant networks to transmit high energy quantities on long distances from gas deposit to consumption areas. Considering European Transmission Pipelines only, the onshore network mileage has been multiplied by more than three times between 1970 and 2007 [1].

The pipeline safe operation and high reliability depend on various factors - mechanical damages or external interferences, fatigue cracks, material defects, weld cracks, improper welding, internal or external corrosion and most of all on the ageing of the physical state of the pipeline metal and welded joints during their prolonged exploitation. The damages caused by human error or vandalism are not infrequent also.

One notes that mechanical damage (external interference) is the major cause of service failures in Europe in transmission pipelines. This kind of damage can be classified into gouges and dents. A combination of a dent and gouge is generally accepted as the most dangerous defect and its behaviour not fully understood.

The main objective of this study is to examine the influence of two types of defects on burst pressure of A37 steel pipes:

-dent

-combination of dent and gouge

\section{Experimental study}

Pressure vessels have been made with pipe piece of length $L=600 \mathrm{~mm}$, thickness $t=3.2 \mathrm{~mm}$ and external diameter $\mathrm{De}=88.9 \mathrm{~mm}$. Pipe ends are covered with caps. A valve is welded on one cap in order to apply an internal water pressure.

One specimen without defect was burst in order to measure the reference burst pressure, which was found equal to $31.1 \mathrm{MPa}$.

For all other specimens, a dent has been obtained by applying a rigid spherical indenter with 40 mm diameter at low strain rate using a tension testing machine. For the specimens containing a combination of dent and gouge, the gouge was made with Electrical Discharge Machining before the indentation.

\section{Numerical simulation}

A finite element simulation using ABAQUS software has been realised for both defects in order to interpret test results. 
The pipe models were constructed using 8-nodes hexahedral elements.

Elasto-plastic behaviour was modelled using an isotropic strain hardening law. Three steps analysis has been used in order to reproduce the experimental conditions:

-First step: the pipe is dented with a rigid spherical indenter

-Second step: the indenter is removed. One can note a spring-back phenomenon

-Third step: pressurization of the dent pipe. The dent move outwards allowing the pipe to regain its circular shape.

\section{Results}

Five specimens containing a dent were tested. Dent geometries and critical pressures for the 5 tests are given in table 1 . We note that there is no effect of dent depth on burst pressure. Critical pressure is close to limit pressure obtained without defect. Moreover, it can be noted that failure occurs on other place than dent as we can see on Fig. 1.

Table 1: Geometries and burst pressures for dent defect.

\begin{tabular}{|l|c|c|c|c|c|}
\hline Vessel number & 1 & 2 & 3 & 4 & 5 \\
\hline Dent depth $(\mathrm{mm})$ & $25\left(\approx_{28 \%}\right.$ & $14(\approx 16 \%$ & $11.85(\approx$ & $8.94(\approx$ & $8.9(\approx 10 \%$ \\
& $\left.\mathrm{De}_{\mathrm{e}}\right)$ & $\left.\mathrm{De}_{\mathrm{e}}\right)$ & $13 \% \mathrm{De})$ & $\left.10 \% \mathrm{De}_{\mathrm{e}}\right)$ & $\left.\mathrm{De}_{\mathrm{e}}\right)$ \\
\hline Burst pressure $(\mathrm{MPa})$ & 31.3 & 31.0 & 31.6 & 30.8 & 31.0 \\
\hline
\end{tabular}

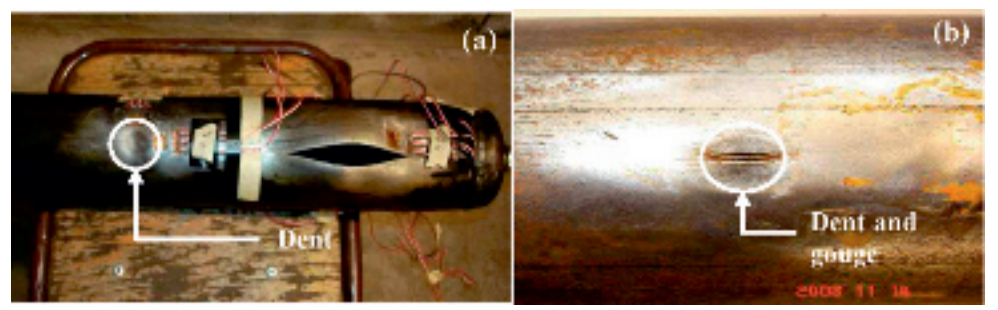

Fig. 1: Typical burst test results for a vessel containing: (a): dent; (b): dent and gouge

OYANE's criterion [2] has been used and implemented in ABAQUS software in order to predict damage and failure of dented pipe. The values of OYANE's criterion never reach the critical value, that for dent depth going up to $28 \mathrm{~mm}(\approx 30 \% \mathrm{De})$, before and after pressurization. Four specimens containing a dent and gouge defect have been tested. The gouge had always the same geometry (length $=6.4 \mathrm{~mm}$, depth= $1.6 \mathrm{~mm}$, notch radius $=1 \mathrm{~mm}$ ). The dents depth equals to $16 \% \mathrm{De}, 13 \% \mathrm{De}$, $10 \%$ De and 3\% De respectively. Experimental results have been treated with a semi-local failure criterion denoted "volumetric method" which is based on the notch stress intensity factor concept. This method was developed in LaBPS (Laboratoire de Mécanique Biomécanique Polymere et Structures) [3].

\section{References}

17 th Report of European Gas Pipeline Incident Data Group, 6th EGIG Report, December 2008.

2 M. Oyane, T.Sato, K. Okimoto, S. Shima, Criteria for ductile fracture and their application, J. Mech. Work technol. 4, 1980.

3 H.Adib, S.Jallouf, C.Schmitt, A.Carmassol, G.Pluvinage, Evaluation of the effect of corrosion defects on the structural integrity of X52 gas pipelines using the SINTAP procedure and notch theory; Int.J.Press.Vess.Pip., vol 84, 3, pp 123-131,2007. 